\title{
O ICMS ESPORTIVO E O FINANCIAMENTO DAS POLÍTICAS MUNICIPAIS DE ESPORTE EM MINAS GERAIS
}

\author{
EL ICMS DEPORTIVO Y LA FINANCIACIÓN DE LAS POLITICAS MUNICIPALES \\ DE DEPORTE EN MINAS GERAIS
}

SPORTS SALES TAX AND FUNDING OF SPORTS POLITICS IN MINAS GERAIS

Rafael Silva Diniz*, Luciano Pereira da Silva*

Palavras-chave Esportes.

Políticas públicas. Financiamento governamental. Impostos.
Resumo: $O$ Imposto sobre Circulação de Mercadorias e Serviços (ICMS) é um tributo arrecadado pelos governos estaduais e parcialmente distribuído aos municípios. No caso de Minas Gerais, a partilha se dá através de diversos critérios, dentre eles o denominado ICMS Esportivo. $O$ objetivo deste estudo é discutir o papel desse tributo no financiamento das políticas de esporte, a partir dos documentos oficiais que ordenam o funcionamento do ICMS e dos dados públicos da partilha desse recurso, entre 2011 e 2014. O estudo conclui que tal estratégia de financiamento público possui diversos limites, como a demasiada valorização dos eventos municipais esportivos.
Palabras clave Deportes. Políticas públicas. Financiación gubernamental. Impuestos.
Resumen: El Impuesto sobre Circulación de Mercaderías y Servicios (ICMS) es un tributo recaudado por los gobiernos de los Estados y parcialmente distribuido a los municipios. En el caso de Minas Gerais, esa distribución se da según diversos criterios, entre los cuales el denominado ICMS Deportivo. El objetivo del presente estudio es discutir papel de este tributo en la financiación de las políticas de deporte a partir de documentos oficiales que ordenan el funcionamiento del ICMS y de los datos públicos sobre la distribución de esos recursos entre 2011 y 2014 . El estudio concluye que tal estrategia de financiación pública tiene diversos límites, como excesiva valorización de los eventos municipales deportivos.

\section{Keywords}

Sports.

Public policies.

Funding, government. Taxes.
Abstract: The Brazilian sales tax known as Tax on Circulation of Merchandise and Services (Imposto Sobre Circulação de Mercadorias e Serviços - ICMS) is collected by state governments and partially distributed to municipalities. In the case of the state of Minas Gerais, this distribution happens under several criteria, including Sports ICMS (ICMS Esportivo). The purpose of the study is to discuss the role of that tax in funding sports policies based on official documents describing ICMS operation and public data on its distribution between 2011 and 2014. The study concludes that such public funding strategy has several constrains, such as overvaluing sports municipal events.
* Universidade Federal de Minas Gerais. Belo Horizonte, MG, Brasil. E-mail: paje_Itda@yahoo.com.br

Recebido em: 23-04-2016 Aprovado em: 06-09-2016 (c) (1) (8) Licence 


\section{INTRODUÇÃO}

No Brasil, a década de 1980 foi marcada pelo processo de redemocratização política e pela discussão que envolveu a elaboração de uma nova Constituição. A Carta Magna de 1988, conhecida como Constituição Cidadã, inova em diversos aspectos, entre eles, 0 estabelecimento do esporte como um direito social.

Pelo fato do esporte passar a ser um direito, intensificam-se as demandas da sociedade por ações governamentais direcionadas a ele. Tais ações, ou seja, as políticas públicas de esporte, conformam-se a partir de uma série de fatores, como o tipo de relacionamento que os governantes estabelecem com a população e as verbas públicas destinadas a este setor. Nesse sentido, é importante reconhecer que o tema financiamento esportivo é decisivo para a materialização das políticas públicas de esporte. Apesar da sua importância, são escassos os estudos acadêmicos que se debruçam sobre o tema (ATHAYDE; MASCARENHAS; SALVADOR, 2015).

Neste contexto, o presente trabalho destaca um aspecto central da política de esporte do Estado de Minas Gerais, o ICMS Esportivo. A partir do ano de 2010, o Esporte passou a ser um dos parâmetros de partilha da quarta parte do Imposto sobre Circulação de Mercadorias e Serviços (ICMS), que a Constituição Federal permite aos estados subnacionais legislar. 0 ICMS é um tributo arrecadado pelo governo estadual e parcialmente distribuído aos municípios mineiros. $O$ objetivo do estudo é discutir sobre o papel do ICMS Esportivo no financiamento das políticas municipais de esporte, problematizando os limites do alcance dessa política.

Para atingir o objetivo, foram utilizados documentos oficiais do Estado de Minas Gerais que ordenam o funcionamento do ICMS, além de dados apurados no Critério Esporte para o período compreendido entre 2011 e 2014. Cabe mencionar que, apesar de os municípios passarem a pontuar em 2010, o repasse do recurso somente acontece no ano subsequente, por isso 2011 é o primeiro ano de análise do estudo.

$\mathrm{O}$ artigo está dividido em três partes. Na primeira é discutida a forma de distribuição de tributos no país, a partir do texto constitucional. Na segunda seção é abordado o caso mineiro de distribuição do ICMS, tendo como foco um dos 18 critérios adotados pelo Estado de Minas Gerais, o esporte. Por fim, na terceira parte, são analisados os dados das transferências financeiras realizadas aos municípios mineiros que pontuaram no critério esporte do ICMS. Tratase de uma abordagem quantitativo-qualitativa dos dados disponibilizados no site da Fundação João Pinheiro ${ }^{1}$. Na discussão dos dados apresentados, busca-se destacar as potencialidades e ressalvas em relação à utilização do critério esporte do ICMS para democratizar a distribuição dos recursos financeiros no estado de Minas Gerais. Para verificar o resultado da indução do ICMS esportivo na política municipal, foram verificadas as atividades cadastradas pela cidade de Rio Novo, município com o melhor valor per capita no acumulado do período de 20112014, as quais estavam disponíveis no Relatório de "Indicadores Esportivos do ICMS Solidário Critério Esportes de 2013".

\section{FINANCIAMENTO DAS POLÍTICAS PÚBLICAS MUNICIPAIS}

O município é peça fundamental no processo de descentralização da política pública no país, tanto que a Constituição Federal de 1988 inovou no aspecto jurídico ao horizontalizar

1 Disponivel em: <http://www.fjp.mg.gov.br/robin-hood>. Acesso em: 14 jun. 2015. 
a relação hierárquica e the atribuir o status de ente federativo, conforme consta no Art. 1:. "[...] a República Federativa do Brasil, formada pela união indissolúvel dos Estados e Municípios e do Distrito Federal, constitui-se em Estado Democrático de Direito [...]" (BRASIL, 1988, online).

Mas, apesar do aumento na gama de atividades e serviços de caráter público sobre a responsabilidade dos municípios, a descentralização da arrecadação dos recursos não acompanhou a mesma lógica. De acordo com Cossío (1998), a forma como foi organizada a tributação municipal dificulta a efetivação das suas novas atribuições constitucionais. Isso porque os tributos de competência dos municípios são arrecadados, quase que exclusivamente, em municípios urbanos e de grande porte populacional (acima de 50 mil habitantes), o que é realidade de apenas 638 (11,5\%) dos 5570 municípios existentes no país (INSTITUTO BRASILEIRO DE GEOGRAFIA E ESTATÍSTICA, 2014, p.120). A consequência disso é que grande parte dos municípios depende da receita de transferência compulsória.

No âmbito federal, temos a transferência de $22,5 \%$ do valor arrecadado com o Imposto de Renda (IR), pessoa física e jurídica, para o Fundo de Participação dos Municípios. Já, 2,5\% do Imposto sobre Produtos Industrializados (IPI) são destinados ao Fundo de Exportação dos Municípios. E, por fim, o governo federal devolve ao município onde incide o tributo 50\% do Imposto sobre Propriedade Territorial Rural (ITR).

Tabela 1 - Receita de impostos e partilha no âmbito federal

\begin{tabular}{ll}
\hline \multicolumn{1}{c}{ Nível de Governo: UNIÃO } & \multicolumn{1}{c}{ Transferência Compulsória } \\
\hline - Imposto sobre Importação (II) & \\
- Imposto sobre Exportação (IE) & \\
- Imposto sobre Operações Financeiras (IOF) & \\
- Imposto sobre Grandes Fortunas (IGF) & \\
- Imposto sobre Propriedade Territorial Rural (ITR) & $50 \%$ para os Municípios \\
- Imposto sobre a Renda (IR) & $21,5 \%$ para o Fundo de Participação dos Estados \\
& $22,5 \%$ para o Fundo de Participação dos Municípios \\
- Imposto sobre Produtos Industrializados (IPI) & $7,5 \%$ para o Fundo de Exportação dos Estados \\
& $2,5 \%$ para o Fundo de Exportação dos Municípios \\
\hline
\end{tabular}

Fonte: Elaboração própria: BRASIL (1988).

Por sua vez, no âmbito estadual, temos a transferência compulsória de $50 \%$ do valor arrecadado com o Imposto sobre Veículos Automotores (IPVA) para o município de origem do veículo e devolução de $25 \%$ do valor do Imposto sobre Circulação de Mercadorias e Serviços $\left(\mathrm{ICMS}^{3}\right)$.

Tabela 2 - Receita e impostos e partilha no âmbito estadual

\begin{tabular}{lc}
\hline \multicolumn{1}{c}{ Nível de Governo: ESTADUAL } & Transferência Compulsória \\
\hline - Imposto sobre Circulação de Mercadorias e Serviços (ICMS) & $25 \%$ para os Municípios \\
- Imposto sobre Veículos Automotores (IPVA) & $50 \%$ para os Municípios \\
- Imposto sobre Transmissão causa mortis e Doação (ITCMD) & \\
\hline
\end{tabular}

Fonte: Elaboração própria: BRASIL (1988).

2 Imposto ainda não instituído por lei complementar, embora conste no inciso VII, do art. 153 da Constituição Federal de 1988 30 ICMS foi instituído pelo inciso II, Art. 155 da Constituição Federal de 1988 e recebeu nova redação, com ampliação dos objetos de sua incidência, pela Emenda Constitucional N.ㄱ 3, de 1993, passando a denominar: Imposto sobre operações relativas à circulação de mercadorias e sobre prestações de serviços de transporte interestadual, intermunicipal e de comunicação. 
Esse segundo tributo, o ICMS, tem um grande potencial de arrecadação para os estados subnacionais e, consequentemente, para os municípios, tornando-se uma importante fonte de financiamento das políticas públicas municipais. A forma como é feita a partilha do ICMS está estabelecida na Constituição Federal de 1988, porém, é permitido que o Estado legisle sobre a transferência de até um quarto do recurso (quarta parte).

Art. 158. Pertencem aos Municípios:

IV - vinte e cinco por cento do produto da arrecadação do imposto do Estado sobre operações relativas à circulação de mercadorias e sobre prestações de serviços de transporte interestadual e intermunicipal e de comunicação.

Parágrafo único. As parcelas de receita pertencentes aos Municípios, mencionadas no inciso IV, serão creditadas conforme os seguintes critérios:

I - três quartos, no mínimo, na proporção do valor adicionado nas operações relativas à circulação de mercadorias e nas prestações de serviços, realizadas em seus territórios;

II - até um quarto, de acordo com o que dispuser lei estadual ou, no caso dos Territórios, lei federal (BRASIL, 1988, online).

No caso de Minas Gerais, a partir de 1991, passou-se a utilizar o Decreto-Lei Estadual N. -32.771 para distribuir a quarta parte do ICMS aos municípios, sendo que se adotaram três critérios: 94,0668\% ao Valor Adicionado Fiscal (VAF), 5,61\% aos Municípios Mineradores e 0,3232\% à Compensação Financeira por Desmembramento de Distrito. De acordo com Riani (2000), a distribuição baseada nesses critérios demonstrou um alto grau de concentração de recursos nos municípios mais desenvolvidos e mais ativos economicamente, tanto que, ao analisarem-se os dados de transferência de 1993, percebeu-se que 51 municípios mineiros recebiam $72 \%$ de todo o recurso disponível da quarta parte do ICMS. Dessa forma, grande parte dos municípios continuou com pouco recurso para desenvolver suas políticas públicas e colocar em prática suas novas atribuições constitucionais.

Com base nessa constatação, criou-se o consenso de que era necessário alterar os critérios de rateio, e uma nova legislação passou a ser discutida na Assembleia Legislativa de Minas Gerais. Em 28 de dezembro de 1995, foi publica a Lei Estadual № 12.040, que ampliou os critérios para a partilha do ICMS: Valor Adicionado Fiscal (VAF), População (PP), Área Geográfica (PA), Educação (PE), Saúde (PS), Receita Própria Municipal (PRP), Agricultura Área Cultivada (PAC), Patrimônio Cultural (PPC), Fator Ambiental (PMA) e Cota Mínima (PCM) (MINAS GERAIS, 1995). Essa legislação ficou conhecida como Lei Robin Hood, pois visava desconcentrar a transferência de recurso dos grandes municípios para as regiões mais pobres, além de adotar parâmetros técnicos para estimular a aplicação de recursos municipais nas áreas sociais básicas (FUNDAÇÃO JOÃO PINHEIRO, 2010a).

Os critérios ainda sofreram algumas adequações na distribuição (Lei Estadual № 12.42/1996, Lei Estadual № 13.803/2000), mas somente com a Lei Estadual № 18.030/2009 veio a sofrer alteração significativa, ao incluir seis novos parâmetros de partilha: turismo, esportes, municípios sede de estabelecimentos penitenciários, recursos hídricos, ICMS solidário e mínimo per capita, além do subcritério mata seca ao ICMS Ecológico. A nova legislação, que passou a ser chamada de ICMS Solidário, entrou em vigor em janeiro de 2010, com a apuração da pontuação dos municípios e distribuição do recurso ano seguinte, 2011 (FUNDAÇÃO JOÃO PINHEIRO, 2010a). 


\section{ICMS ESPORTIVO EM MINAS GERAIS}

De acordo com a Fundação João Pinheiro (2010b, p.15), o objetivo do critério esporte na partilha da quarta parte do ICMS é "[...] incentivar a criação e manutenção de programas voltados para o desenvolvimento de atividades esportivas no município". Todavia, a legislação colocou como requisito para os municípios acessarem esse recurso a criação e pleno funcionamento do Conselho Comunitário de Esportes.

Subseção VII - Do Critério "Esportes"

Art. $8^{\circ}-[\ldots]$

$\S 1^{\circ}$ - Somente participam deste critério os Municípios que instalarem e mantiverem em pleno funcionamento o Conselho Comunitário de Esportes, o qual deverá elaborar e desenvolver, em conjunto com a Prefeitura Municipal, os projetos destinados à promoção das atividades esportivas, bem como fiscalizar a sua execução (MINAS GERAIS, 2009, online).

No descritivo da lei, notamos que o Conselho é do tipo deliberativo, ou seja, tem poder de interferência nas políticas públicas municipais de esporte. Porém, no manual para criação de Conselhos Municipais de Esporte ${ }^{4}$, disponibilizado pela Secretaria de Estado de Turismo e Esporte (SETES), é caracterizado o conselho como um "[...] órgão colegiado de caráter consultivo" (MINAS GERAIS, 2010, p.4). Isto é, suas decisões sobre as políticas públicas de esporte não precisam ser acatadas pelo gestor municipal, prevalecendo as alternativas selecionadas pelo poder público.

Além disso, a origem popular dos conselhos como local de exercício da democracia participativa é minimizada por uma orientação tecnicista, que coloca como primeiro passo para a criação do Conselho um projeto de lei proposto pelo Poder Executivo e ratificado pelo Poder Legislativo. No caso de dificuldade em mobilizar as pessoas para criação do Conselho, é sugerida a inclusão da temática esportiva a outro Conselho já existente no município (MINAS GERAIS, 2010).

A comprovação do pleno funcionamento do Conselho Municipal de Esporte é feita pela apresentação da Lei ou Decreto municipal de criação do Conselho ou sua alteração; Ata de nomeação dos conselheiros atuais; Ata da reunião de posse dos membros atuais do Conselho, devidamente datada e assinada por todos os presentes; Duas Atas de reuniões ordinárias ocorridas no ano base, no mínimo, devidamente datadas e assinadas por todos os presentes; Regimento Interno atualizado (MINAS GERAIS, 2013; MINAS GERAIS, 20155). Toda a documentação deve ser apresentada à SETES até 0 dia 30 de abril. 0 cadastro e status dos Conselhos Municipais de Esporte podem ser verificados no Sistema de Gestão Esportiva Municipal no sítio www.icms.esportes.mg.gov.br.

Vale destacar a importância dos Conselhos para a garantia dos direitos (entre eles, 0 esporte) como um espaço híbrido de participação do Estado e sociedade. Criados no Brasil a partir do final dos anos 1970, por iniciativa de governantes ou da própria população, esses órgãos podem se configurar como mecanismo importante de fiscalização e proposição da população diante da administração pública.

Nas diretrizes para criação e funcionamento do Conselho Municipal de Esporte, para que os municípios mineiros acessem o ICMS Esportivo, não existe a garantia de que este órgão 
irá de fato ampliar o processo de democratização das políticas de esporte nos municípios. Isto porque a existência do órgão independe de questões fundamentais, como, por exemplo, a sua competência e composição.

No Gráfico 1 percebemos 0 aumento na quantidade de municípios habilitados no critério esporte, o que demonstra a popularização do mecanismo no Estado de Minas Gerais. Nesse quesito, temos que destacar a divulgação realizada pela SETES, mas também 0 trabalho do Ministério Público, que tem notificado alguns gestores municipais com base na Lei de Responsabilidade Fiscal (Lei Complementar N ․ 101/2000), a qual caracteriza como crime fiscal a renúncia de receita por negligência.

Gráfico 1 - Frequência de municípios participantes no ICMS Esportivo

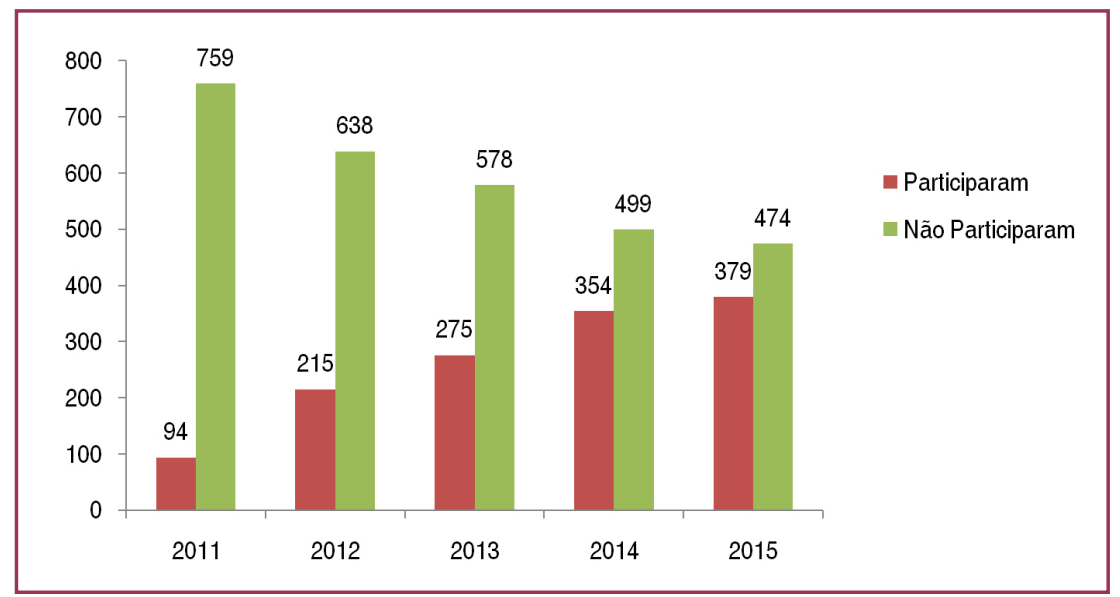

Fonte: Elaboração própria: SETES $(2015$, p.1)

Embora tenha crescido a quantidade de municípios cadastrados, ainda existe uma lacuna muito grande para ser preenchida, pois apenas 44\% (379) dos municípios mineiros participam do ICMS Esportivo, enquanto outros 56\% (474) têm desconsiderado esta fonte de receita tributária.

Anualmente, o critério esporte é responsável pela transferência de $0,10 \%$ da quarta parte do ICMS arrecadado pelo Estado de Minas Gerais para os municípios habilitados e que nele pontuam. O Gráfico 2 mostra os valores totais transferidos pelo critério, sendo que 0 ano de 2015 refere-se a uma estimativa da Secretaria Estadual de Fazenda (SEF).

Gráfico 2 - Montante do repasse aos municípios pelo critério esporte do ICMS

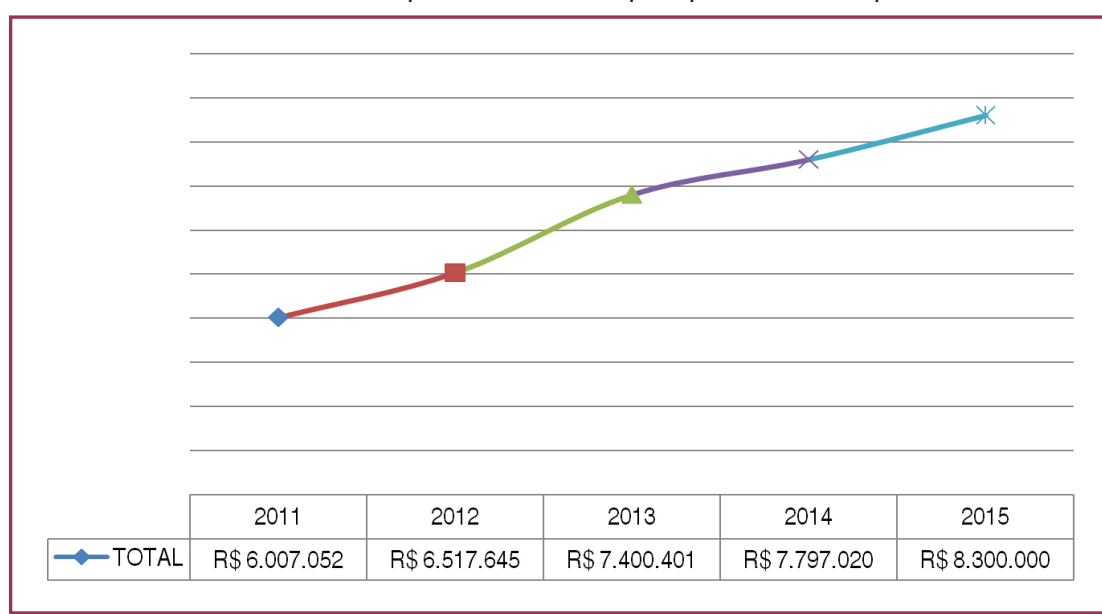

Fonte: Elaboração própria: SETES (2015, p.1). 
A SETES é o órgão do Estado encarregado de fiscalizar e normatizar os procedimentos para apuração da pontuação dos municípios. Até o dia 15 de julho o índice provisório referente ao ano anterior deve ser divulgado e até o dia 15 de agosto, o índice definitivo. 0 cálculo do índice anual utiliza a seguinte fórmula:

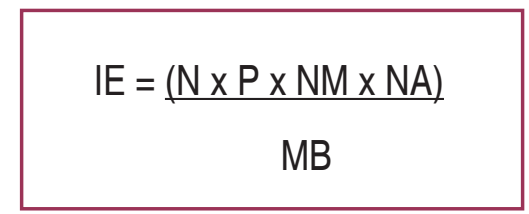

Onde:

a) IE = Índice de Esportes do Município;

b) $\mathrm{N}=$ Nota da atividade esportiva desenvolvida pelo município (o quadro com a nota de cada atividade esportiva encontra-se no anexo V da Lei Estadual N. ${ }^{\circ}$ 18.030/2009);

c) $\mathrm{P}=$ Peso da receita corrente líquida per capita (tabela com a relação das faixas de receita corrente líquida per capita e seus respectivos pesos é publicada anualmente pela Fundação João Pinheiro);

d) NM = Número de modalidades esportivas de que o município participa em cada atividade

esportiva;

e) NA = Número de atletas participantes em cada atividade esportiva;

f) $\mathrm{MB}=$ Somatório das notas de todos os municípios beneficiados.

A nota da atividade esportiva desenvolvida pelo município (N) é o somatório de 13 categorias elencadas pela SETES, sendo que a nota pode variar de 0 a 10 pontos. Para pontuar em uma dessas categorias, o município precisa desenvolver ao menos uma atividade dentro dos requisitos contidos na Resolução SEEJ N ․ำ13/2013.

Tabela 3 - Nota da atividade esportiva desenvolvida pelo município

\begin{tabular}{lc}
\hline \multicolumn{1}{c}{ Atividade } & Nota \\
& (Pontos) \\
\hline $\begin{array}{l}\text { Construção ou Reforma de Instalação/ Aquisição e disponibilização de equipamento esportivo } \\
\text { (IREE) }\end{array}$ & 0,5 \\
Programas Socioeducacionais (PSE) & 0,5 \\
Xadrez na Escola (XE) & 0,5 \\
Academia na Escola (AE) & 0,5 \\
Minas Olímpica Jogos de Minas Gerais (JIMI) & 0,5 \\
Atividades de futebol amador (AFA) & 0,5 \\
Atividades de Lazer (AL) & 0,5 \\
Esporte para Pessoas com Deficiência (EPD) & 1,0 \\
Esporte Terceira Idade (ETI) & 1,0 \\
Jogos Escolares Municipais (JEM) & 1,0 \\
Minas Olímpica Jogos Escolares de Minas Gerais (JEMG) & 1,0 \\
Qualificação Agente Esportivo (QAE) & 1,0 \\
Outros Programas/Projetos (PP) & 1,5 \\
\hline
\end{tabular}

Fonte: Minas Gerais (2010, p.5-6) - adaptado. 
As categorias possuem pesos diferentes, variando de 0,5 a 1,5 ponto, mas não existe uma classificação clara do porquê da escolha dessas categorias ou da diferença de peso entre elas. Aparentemente, as categorias com maior peso seriam as de maior grau de importância para a política esportiva estadual. Nesse sentido, a categoria "Outros Programas/ Projetos (PP)", a única com 1,5 ponto, seria extremamente relevante. Na sua descrição, temos o desenvolvimento do esporte de rendimento por meio do apoio municipal, a promoção de competições regionais e/ou a participação de seus atletas em competições oficiais (organizadas pelas federações ou confederações esportivas). Ou seja, existe uma priorização na indução do Estado de Minas Gerais ao desenvolvimento do esporte de rendimento em prol das manifestações educacionais e/ou de lazer, o que tende a beneficiar uma pequena parcela da população e privilegiar os setores mais conservadores do esporte (MATIAS et al. 2015). Além disso, tal constatação contraria o texto da Constituição Federal de 1988, reforçado pelo inciso I, do Art. 218 da Constituição do Estado de Minas Gerais, que expõe como prioridade estatal o apoio ao esporte educacional (BRASIL, 1988; MINAS GERAIS, 2016).

Para pontuar nesta categoria, também existe a possibilidade do município criar legislação de incentivo fiscal ou fundo de financiamento ao esporte. No entanto, para Cossío (1998), os municípios interioranos possuem baixa capacidade tributária, o que, neste caso, poderia ser um fator limitante para elaboração de uma política de financiamento focal. Logo, estas alternativas favoreceriam apenas os municípios urbanos e de grande porte populacional.

Já os critérios de relevância intermediária, com 1,0 ponto cada, podem ser divididos entre atendimento a um público especifico: pessoa com deficiência e terceira idade - acima de 60 anos; ou Eventos esportivos escolares: Jogos escolares municipais ou estaduais (JEMG); ou qualificação dos agentes envolvidos no esporte municipal.

Por último, teríamos os critérios com a menor relevância, com 0,5 ponto cada, nos quais talvez esteja mais confusa a adoção dos critérios. Um primeiro critério, o "Programas Socioeducacionais (PSE)", visa apurar as atividades esportivas ao público jovem, realizadas no contraturno escolar, mas não define o local onde estas devem acontecer (dentro ou fora da escola). Já os critérios "Xadrez na Escola" e "Academia na escola" também devem acontecer no contraturno escolar, embora essa informação não esteja explícita na resolução, porém, a atividade deve acontecer no ambiente escolar. Ora, se a finalidade desses três itens é o foco educacional e socializante ocasionado pela prática esportiva, será que o local ou modalidade esportiva (xadrez, "escolinhas" de esporte, etc.) é tão importante a ponto de ser desmembrado em três critérios distintos? Esse é um questionamento que talvez encontre parte da resposta no resgate do debate que envolveu a construção dos critérios, mas que não é objetivo deste artigo.

Ainda em relação aos critérios de 0,5 ponto, temos o "Minas Olímpica", os "Jogos de Minas Gerais (JIMI)" e "Atividades de futebol amador (AFA)", que visam apurar as atividades do esporte de rendimento não profissional nos municípios. Já o critério "Atividades de Lazer (AL)" está descrito com objetivo de promoção da saúde, ou seja, as práticas realizadas no lazer precisam ter uma finalidade (lazer utilitarista), pois o objeto lazer não é compreendido como um direito em si mesmo. E o último critério seria "Construção ou Reforma de Instalação/ Aquisição e disponibilização de equipamento esportivo (IREE)", o qual tem a particularidade de ser subdividido em: I - construção de instalação esportiva (0,25 ponto), II - reforma de instalação esportiva (0,15 ponto); e III - aquisição e disponibilização de equipamento esportivo (0,10 ponto). 
Outro elemento existente na fórmula de cálculo do Índice Esportivo (IE) é o peso da receita corrente líquida per capita $(\mathrm{P})$, que é calculado pela Fundação João Pinheiro. A receita corrente refere-se à divisão do montante de arrecadação do município pelo total da sua população, ou seja, tem-se um valor relativo sobre a riqueza da localidade. A fim de minimizar a desigualdade econômica no estado, o Índice Esportivo (IE) privilegia com uma pontuação maior os municípios com pior classificação, assim, uma mesma prática esportiva terá um peso maior naquelas cidades com menor receita.

Tabela 4 - Pontuação para Receita Corrente Líquida

\begin{tabular}{cc}
\hline Receita Corrente Líquida (RCL) "Per Capita” (em R\$) & Nota \\
\hline acima de $3.974,06$ & 1 \\
$2.649,37$ a $3.974,06$ & 2 \\
$1.987,03$ a $2.649,37$ & 3 \\
$1.821,44$ a $1.987,03$ & 4 \\
$1.655,86$ a $1.821,44$ & 5 \\
$1.490,27$ a $1.655,86$ & 6 \\
$1.324,69$ a $1.490,27$ & 7 \\
$1.159,10$ a $1.324,69$ & 8 \\
993,52 a $1.159,10$ & 9 \\
0,00 a 993,52 & 10 \\
\hline
\end{tabular}

Fonte: Minas Gerais (2012, p.1) - adaptado

O terceiro elemento da fórmula trata do "número de modalidades esportivas de que o município participa em cada atividade esportiva (NM)". Essa pontuação pode variar de 1 a 10 pontos, dependendo da quantidade de modalidades. Trata-se de uma iniciativa para tentar diversificar a cultura esportiva local, porém desconsidera o nível de dificuldade na organização dos esportes coletivos e individuais. Nesse sentido, um jogo amistoso de futebol, que envolve no mínimo 22 participantes (11 em cada equipe), tem o mesmo peso que uma luta amistosa de judô praticada por dois participantes. Tal fato pode induzir a gestão municipal a optar por diversos eventos menores de modalidade individual para obter uma maior pontuação, muito embora a abrangência populacional seja um dos fatores primordiais para a concepção de democratização do direito social ao esporte.

Tabela 5 - Pontuação para número de modalidades esportivas

\begin{tabular}{cc}
\hline Número de Modalidades Esportivas & Nota \\
\hline 1 & 1 \\
2 & 2 \\
3 & 3 \\
4 & 4 \\
5 & 5 \\
6 a 7 & 6 \\
8 a 9 & 7 \\
10 a 11 & 8 \\
12 a 14 & 9 \\
Acima de 15 & 10 \\
\hline
\end{tabular}


Contudo, o quarto elemento trata do "número de atletas participantes em cada atividade esportiva (NA)", sendo que a pontuação pode variar de 1 a 10 pontos. 0 quantitativo de participantes envolvidos necessário para receber a pontuação depende do tamanho populacional do município. Todavia, não há uma diferenciação entre modalidade de esporte coletivo ou individual, sendo que desta vez existe uma tendência pela escolha da modalidade coletiva, por agrupar um número maior de praticantes.

Por outro lado, o cálculo desse elemento leva em consideração apenas os praticantes, não sendo sensível a outras formas de fruição do direito social ao esporte e lazer, tais como 0 assistir e o torcer. Vale lembrar que essa outra forma de usufruir do esporte é relevante, tanto que, de maneira inovadora, o governo argentino tornou pública (estatizou) a transmissão das partidas de várias modalidades esportivas no país, como uma forma de acesso à herança cultural da sociedade (FERRAZ, 2011; MARSHALL, 1967).

Tabela 6 - Pontuação para número de participantes em cada atividade

\begin{tabular}{|c|c|c|c|c|c|c|}
\hline \multirow[b]{2}{*}{ Pontos } & \multicolumn{6}{|c|}{ Número de atletas participantes em cada atividade esportiva } \\
\hline & $\begin{array}{l}\text { Até } 10 \text { mil } \\
\text { hab. }\end{array}$ & $\begin{array}{c}10 \text { a } 20 \text { mil } \\
\text { hab. }\end{array}$ & $\begin{array}{l}20 \text { a } 50 \text { mil } \\
\text { hab. }\end{array}$ & $\begin{array}{c}50 \text { a } 100 \text { mil } \\
\text { hab. }\end{array}$ & $\begin{array}{c}100 \text { a } 500 \text { mil } \\
\text { hab. }\end{array}$ & $\begin{array}{l}\text { Mais de } 500 \\
\text { mil hab. }\end{array}$ \\
\hline 1 & até 25 & até 50 & até 75 & até 100 & até 125 & até 150 \\
\hline 2 & 26 a 50 & 51 a 100 & 76 a 150 & 101 a 200 & 126 a 250 & 151 a 300 \\
\hline 3 & 51 a 75 & 101 a 150 & 151 a 225 & 201 a 300 & 251 a 375 & 301 a 450 \\
\hline 4 & 76 a 100 & 151 a 200 & 226 a 300 & 301 a 400 & 376 a 500 & 451 a 600 \\
\hline 5 & 101 a 125 & 201 a 250 & 301 a 375 & 401 a 500 & 501 a 625 & 601 a 750 \\
\hline 6 & 126 a 150 & 251 a 300 & 376 a 450 & 501 a 600 & 626 a 750 & 751 a 900 \\
\hline 7 & 151 a 175 & 301 a 350 & 451 a 525 & 601 a 700 & 751 a 875 & 901 a 1050 \\
\hline 8 & 176 a 200 & 351 a 400 & 526 a 600 & 701 a 800 & 876 a 1000 & 1051 a 1200 \\
\hline 9 & 201 a 225 & 401 a 450 & 601 a 675 & 801 a 900 & 1001 a 1125 & 1201 a 1350 \\
\hline 10 & acima de 225 & acima de 450 & acima de 675 & acima de 900 & acima de 1125 & acima de 1350 \\
\hline
\end{tabular}

Fonte: Minas Gerais (2013, p.12) -adaptado.

\section{ANÁLISE DA DISTRIBUIÇÃO DO ICMS - CRITÉRIO ESPORTE}

Dentre os dez municípios que mais arrecadaram em valores absolutos nos primeiros quatro anos (2011-2014) de funcionamento do ICMS Esportivo, estão cinco cidades que possuem uma população inferior a 50 mil habitantes, o que demonstra uma possibilidade de democratizar o acesso ao recurso financeiro, embora possa haver problemas nos mecanismos de participação popular e nos critérios de pontuação. De acordo com os dados do Censo do Instituto Brasileiro de Geografia e Estatística de 2010, o estado de Minas Gerais contava com 67 municípios com população superior a 50 mil habitantes. Destes, $17^{6}$ não pontuaram no critério esporte, e, entre os demais, temos 29 destes grandes municípios que não ficaram entre os 50 maiores arrecadadores em valor absoluto do critério esporte.

6 Municípios com população superior a 50 mil habitantes (INSTITUTO BRASILEIRO DE GEOGRAFIA E ESTATÍSTICA, 2010) e que não têm pontuação no critério esporte do ICMS: Contagem, Betim, Divinópolis, Santa Luzia, Ibirité, Araguari, Araxá, Paracatu, Timóteo, Nova Lima, 
Tabela 7 - Maiores arrecadadores do ICMS Esportivo (valores absolutos)

\begin{tabular}{lcc}
\hline \multicolumn{1}{c}{ MUNICÍPIO } & TOTAL (2011-2014) & População 2010 \\
\hline UBERLÂNDIA & $\mathrm{R} \$ 723.913,79$ & 604.013 \\
CATAGUASES & $\mathrm{R} \$ 649.795,81$ & 69.757 \\
CAMPO BELO & $\mathrm{R} \$ 603.788,46$ & 51.544 \\
GUAXUPÉ & $\mathrm{R} \$ 547.318,40$ & 49.430 \\
DIAMANTINA & $\mathrm{R} \$ 532.693,99$ & 45.880 \\
ARCOS & $\mathrm{R} \$ 478.031,07$ & 36.597 \\
ELOI MENDES & $\mathrm{R} \$ 451.028,42$ & 25.220 \\
ITAJUBÁ & $\mathrm{R} \$ 445.040,77$ & 90.658 \\
UBÁ & $\mathrm{R} \$ 437.368,96$ & 101.519 \\
SÃO JOÃO NEPOMUCENO & $\mathrm{R} \$ 436.202,99$ & 25.057 \\
\hline
\end{tabular}

Fonte: Fundação João Pinheiro (2010a); Instituto Brasileiro de Geografia e Estatística (2010) - elaboração própria.

Entretanto, a possibilidade de democratização de parcela do recurso tributário pelo critério esporte talvez fique mais nítida ao dividir-se o valor absoluto pela população do município, ou seja, pelo cálculo do valor per capita da transferência financeira. Nesse sentido, podemos notar na Tabela 8 que os municípios que mais se beneficiariam realmente foram os de população menor, uma vez que, dentre os dez melhores classificados, todos têm uma população inferior a 15 mil habitantes.

Tabela 8 - Maiores arrecadadores do ICMS Esportivo (valores relativos)

\begin{tabular}{lccc}
\hline \multicolumn{1}{c}{ MUNICÍPIO } & TOTAL (2011-2014) & População 2010 & Per capita \\
RIO NOVO & $\mathrm{R} \$ 379.751,22$ & 8.712 & $\mathrm{R} \$ 43,59$ \\
ARICANDUVA & $\mathrm{R} \$ 177.956,70$ & 4.770 & $\mathrm{R} \$ 37,31$ \\
LARANJAL & $\mathrm{R} \$ 188.935,82$ & 6.465 & $\mathrm{R} \$ 29,22$ \\
ANGELÂNDIA & $\mathrm{R} \$ 208.429,60$ & 8.003 & $\mathrm{R} \$ 26,04$ \\
FELÍCIO DOS SANTOS & $\mathrm{R} \$ 133.149,16$ & 5.142 & $\mathrm{R} \$ 25,89$ \\
ITANHANDU & $\mathrm{R} \$ 344.106,56$ & 14.175 & $\mathrm{R} \$ 24,28$ \\
DORES DE CAMPOS & $\mathrm{R} \$ 222.779,88$ & 9.299 & $\mathrm{R} \$ 23,96$ \\
SERRA DA SAUDADE & $\mathrm{R} \$ 19.323,08$ & 815 & $\mathrm{R} \$ 23,71$ \\
MARTINHO CAMPOS & $\mathrm{R} \$ 279.446,85$ & 12.611 & $\mathrm{R} \$ 22,16$ \\
SAPUCAÍ-MIRIM & $\mathrm{R} \$ 135.603,08$ & 6.241 & $\mathrm{R} \$ 21,73$ \\
\hline
\end{tabular}

Fonte: Fundação João Pinheiro (2010a); Instituto Brasileiro de Geografia e Estatística (2010) - elaboração própria.

Desta forma o sistema centralizado de tributação estadual, com partilha pelo critério de desempenho, foi capaz de minimizar a disparidade econômica intermunicipal e ainda estimular a sistematização de dados sobre o esporte desenvolvido localmente. Estamos considerando o somatório das arrecadações do ICMS Esportivo nos quatro anos analisados (2011-2014), porém devemos destacar que, dos 379 municípios inscritos até 2014, somente 75 participaram desde a implantação do critério. Outros 120 municípios pontuaram em três anos, $94 \mathrm{em}$ dois e 90 em apenas um ano. Ou seja, trata-se de um mecanismo ainda muito recente que, embora tenha potencial para aumentar o recurso nos municípios menores, também necessita que sua dinâmica seja melhor apropriada pelos gestores municipais. Além disso, a prefeitura deve possuir uma equipe qualificada e disponível para coletar e lançar as informações no 
sistema, visto que a validação dos dados pela SETES depende de comprovação documental das atividades.

Para verificar as atividades esportivas desenvolvidas e cadastradas no ICMS Esportivo, selecionamos o município de Rio Novo, por ter apresentado o melhor valor per capita de arrecadação no critério, no período acumulado de 2011 a 2014. As informações foram extraídas do relatório do ano de 2013 da SETES, denominado "Indicadores Esportivos do ICMS Solidário Critério Esportes ${ }^{7}$, o documento mais recente disponível durante a realização do estudo.

Ao analisarem-se as atividades, percebe-se que o município pontuou nas seguintes categorias: Atividades de Lazer (280 pontos), Outros Programas e Projetos (840 pontos), Atividades de Futebol Amador (40 pontos), Esporte Terceira Idade (8 pontos), Jogos Escolares Municipais (54 pontos), Esporte para Pessoas com deficiência (8 pontos), Minas Olímpica Jogos Escolares de Minas Gerais (8 pontos). Assim, Rio Novo atingiu um total de 1.208 pontos, ficando em 29일 lugar dentre os habilitados no ano de 2013, com a destinação de 0,80226600298193\% do recurso do ICMS Esportivo.

Dos 2.161 beneficiários das 62 atividades esportivas cadastradas, apenas 15 participantes eram de uma atividade de frequência contínua, enquanto os demais foram beneficiados por participar em algum evento realizado pela própria prefeitura ou apoiado por ela (apoio a evento externo ou ao participante). Assim, a escolha dos elementos de pontuação pela SETES estimulou o município a basear a sua política esportiva em eventos, pois as atividades contínuas pontuam apenas uma única vez, independentemente da duração (um dia a 12 meses). Embora os eventos esportivos sejam importantes para dar visibilidade e incentivar a prática, como política pública exclusiva são uma ação extremamente frágil, pois a permanência do cidadão no esporte depende da sua aquisição pela via do mercado, uma vez que o poder público não disponibiliza a oferta do serviço. Tal constatação está em desacordo com a característica de desmercantilização dos direitos sociais prevista por Menicucci (2006), uma vez que o esporte foi elencado como atributo da nossa herança de cidadania social - nos identifica como brasileiros.

Em relação às modalidades esportivas realizadas pelo município de Rio Novo, temos: Muay Thai, Futsal, Jiu-jítsu, Ginástica Aeróbica, Capoeira, Ciclismo, Futebol Society, Futebol de Campo, Corrida/Maratona, Mountain Bike, Hipismo, Natação, Voleibol, Peteca, Tênis de Mesa, num total de 15 modalidades. Contudo, ainda foi observado um grande peso dos eventos que contemplavam as modalidades corrida de rua e futebol (futebol, futsal, futebol society). Como a análise de estudo de caso focou apenas no relatório de um único ano (2013), não foi possível verificar o comportamento evolutivo na quantidade de beneficiários e/ou de modalidades esportivas no município. Uma investigação longitudinal seria interessante para apontar se o objetivo de diversificação e ampliação no acesso ao direito do esporte desejado pelo SETES tem sido alcançado pela indução das políticas municipais.

\section{CONSIDERAÇÕES FINAIS}

Ao analisarmos os dados financeiros do repasse do ICMS Esportivo, notamos a possibilidade de participação de municípios que estão fora dos grandes centros urbanos, demonstrando o potencial de democratização à distribuição dos tributos públicos. Todavia,

7 Disponível em: <http://www.esportes.mg.gov.br/esportes/icms-solidario-criterio-esportes>. Acesso em: 19 mar. 2015. 
quanto menor o município, maior a dificuldade em se manter uma equipe de servidores públicos capacitados para realizar os registros das atividades. Lembremos que o critério esporte é apenas um dos dezoito existentes no estado de Minas Gerais.

Além disso, os elementos de pontuação, assim como os pesos adotados, não deixam claro qual a trajetória que esta política pretende estimular nas gestões municipais. No caso da análise feita do município de Rio Novo, que apresentou o melhor valor per capita de arrecadação do ICMS Esportivo no acumulado de 2011 a 2014, as faixas etárias de idosos e pessoas com deficiência não receberam atenção e a política social se baseou quase que exclusivamente na realização de eventos. Talvez a falta de um diagnóstico ou de uma política nacional sobre o esporte dificulte o consenso nas diversas esferas de governo (federal, estadual e municipal) sobre a divisão das suas atribuições no esporte e o que deve ser democratizado em relação a esse direito social.

Por fim, por maior que seja a imprecisão da trajetória de estímulo que permeia o ICMS Esportivo, não podemos negar o seu papel de relevância na sistematização e registro das atividades esportivas realizadas no estado, sendo um importante banco de dados para um diagnóstico mais preciso sobre a realidade esportiva em Minas Gerais. Além disso, o ICMS esportivo fomenta a inclusão da temática do esporte na agenda pública municipal.

\section{REFERÊNCIAS}

ATHAYDE, Pedro; MASCARENHAS, Fernando; SALVADOR, Evilásio. Primeiras aproximações de uma análise do financiamento da política nacional de esporte e lazer no Governo Lula. Revista Brasileira de Ciências do Esporte, v. 37, n.1, p. 2-10, jan./mar. 2015.

BRASIL. Presidência da República. Constituição da República Federativa do Brasil de 1988. Brasília, 1988. Disponível em: <http://www.planalto.gov.br/ccivil 03/constituicao/ constituicaocompilado.htm>. Acesso em: 22 mar. 2015.

cossío, Fernando Andrés Blanco. Disparidades econômicas inter-regionais, capacidade de obtenção de recursos tributários, esforço fiscal e gasto público no federalismo brasileiro. Rio de Janeiro: Banco Nacional de Desenvolvimento Econômico e Social, 1998. Disponível em: <http:// www.bndes.gov.br/SiteBNDES/export/sites/default/bndes pt/Galerias/Arquivos/conhecimento/premio/ pr211.pdf>. Acesso em: 26 jun. 2015.

FERRAZ, Lucas. Argentina aumenta programa de estatização do futebol na TV. Folha de S.

Paulo, São Paulo, 25 fev. 2011. Caderno esporte, p.1. Disponível em: <http://m.folha.uol.com.br/ esporte/2011/02/880850-argentina-aumenta-programa-de-estatizacao-do-futebol-na-tv.shtml?mobile>. Acesso em: 27 jul. 2016.

FUNDAÇÃO JOÃO PINHEIRO (FJP). O Histórico da Lei Robin Hood. 12 de fevereiro de 2010a. Disponível em: <http://www.fjp.mg.gov.br/robin-hood/index.php/leirobinhood/historico>. Acesso em: 22 mar. 2015.

FUNDAÇÃO JOÃO PINHEIRO (FJP). Manual ICMS, Centro de Estudos de Políticas Públicas. Belo Horizonte, 12 de agosto de 2010b. Disponível em: <http://www.fjp.mg.gov.br/robin-hood/index.php/ leirobinhood/manual>. Acesso em: 22 mar. 2015

INSTITUTO BRASILEIRO DE GEOGRAFIA E ESTATÍSTICA (IBGE). Perfil dos Municípios Brasileiros 2013: Pesquisa de Informações Básicas Municipais. Rio de Janeiro, 2014. Disponível em: <ftp://ttp.ibge.gov.br/Perfil Municipios/2013/munic2013.pdf>. Acesso em: 19 mar. 2015. 
INSTITUTO BRASILEIRO DE GEOGRAFIA E ESTATÍSTICA (IBGE). Banco de Dados

Agregados. Rio de Janeiro, 2010. Disponível em: < http://www.sidra.ibge.gov.br/bda/popul/default. asp?z=t\&o=25\&i=P $>$. Acesso em: 19 mar. 2015.

MARHALL, Thomas Humphrey. Cidadania e Classe Social. In: MARHALL, Thomas Humphrey. Cidadania, Classe Social e Status. Rio de Janeiro: Zahar. 1967. Cap. 3. Disponível em: <https:/l adm.ufersa.edu.br/wp-content/uploads/sites/18/2014/10/Marshall-Cidadania-Classe-Social-e-Status1. pdf>. Acesso em: 4 mar. 2014.

MATIAS, Wagner Barbosa; ATHAYDE, Pedro Fernando; HÚNGARO, Edson Marcelo; MASCARENHAS, Fernando. A Lei de Incentivo Fiscal e o (não) direito ao esporte no Brasil. Movimento, v.21, n.1, p.95-110, jan./mar. 2015.

MENICUCCI, Telma. Políticas públicas de lazer: questões analíticas e desafios políticos. In: ISAYAMA, Hélder Ferreira; LINHALES, Meily Assbú (Orgs.). Sobre lazer e política: maneiras de ver, maneiras de fazer. Belo Horizonte: Ed. UFMG, 2006. p. 136-163.

MINAS GERAIS. Assembleia Legislativa do Estado de Minas Gerais. Constituição do Estado de Minas Gerais. 16. ed. atualizada e acompanhada dos textos das Emendas à Constituição nos 1 a 94 . Belo Horizonte, 2016. Disponível em: <https:/www.almg.gov.br/opencms/export/sites/default/consulte/ legislacao/Downloads/pdfs/ConstituicaoEstadual.pdf >. Acesso em: 27 jul. 2016.

MINAS GERAIS. Assembleia Legislativa do Estado de Minas Gerais. Lei N. 12.040: Dispõe sobre a distribuição da parcela de receita do produto da arrecadação do ICMS pertencente aos municípios, de que trata o inciso II do parágrafo único do artigo 158 da Constituição Federal, e dá outras providências. Belo Horizonte, 28 de dezembro de 1995. Disponível em: <http://www.fjp.mg.gov.br/ robin-hood/index.php/leirobinhood/legislacao/lei1204095>. Acesso em: 22 mar. 2015.

MINAS GERAIS. Assembleia Legislativa do Estado de Minas Gerais. Lei N.․ 18.030: Dispõe sobre a distribuição da parcela da receita do produto da arrecadação do ICMS pertencente aos Municípios. Belo Horizonte, 12 de janeiro de 2009. Disponível em: <http://www.fjp.mg.gov.br/robin-hood/index.php/ leirobinhood/legislacao/lei1803009->. Acesso em: 22 mar. 2015.

MINAS GERAIS. Secretaria de Estado de Turismo e Esportes de Minas Gerais. Manual para criação de Conselhos Municipais de Esporte. Belo Horizonte, 5 de fevereiro de 2008. Disponível em: $<$ https://drive.google.com/file/d/OBxc1uRb1v1cLcE1acjNDaGQ3emc/view?pli=1>. Acesso em: 22 mar. 2015.

MINAS GERAIS. Site da Secretaria de Estado de Esportes de Minas Gerais. Belo Horizonte, 2015. Disponível em: <http://www.esportes.mg.gov.brl>. Acesso em: 22 mar. 2015.

MINAS GERAIS. Resolução SEEJ № 13/2013 - Dispõe sobre o critério "Esportes" do ICMS SolidárioICMS Esportivo, estabelecido pela Lei 18.030, de 12 de janeiro de 2009 e regulamentado pelo Decreto Estadual $n^{0}$ 45.393. Belo Horizonte, 9 de junho de 2010. Disponível em: < http://www.agenciaminas. noticiasantigas.mg.gov.br/media/uploads/2013/12/16/resolucao-seej-no-13-2013-icms-esportivo.pdf>. Acesso em: 22 mar. 2015.

RIANI, Flávio. A nova experiência de distribuição da Cota-Parte do ICMS aos municípios mineiros. Revista Econômica do Nordeste, v. 31, n. 1 p. 96-107, jan./mar. 2000. Disponível em: <http://www. bnb.gov.br/projwebren/Exec/artigoRenPDF.aspx?cd artigo ren=166>. Acesso em: 22 mar. 2015.

Apoio:

Fundação de Amparo à Pesquisa do Estado de Minas Gerais 